\title{
Is Mental Well-Being in the Oldest Old Different from That in Younger Age Groups? Exploring the Mental Well-Being of the Oldest-Old Population in Europe
}

\author{
Valeria Donisi ${ }^{1}$ - Federico Tedeschi ${ }^{1}$. Juan Luis Gonzalez-Caballero ${ }^{2}$. \\ Johanna Cresswell-Smith ${ }^{3}$. Elvira Lara ${ }^{4,5,6}$. Marta Miret ${ }^{4,5,6}$. Anna K. Forsman ${ }^{7}$. \\ Kristian Wahlbeck ${ }^{3} \cdot$ Francesco Amaddeo $^{1}$. Jorid Kalseth ${ }^{8}$
}

Published online: 14 July 2020

(C) The Author(s) 2020

\begin{abstract}
The oldest-old population is increasing in Europe, and greater focus is placed on promoting mental well-being (MWB) in this population. The European Welfare Models and Mental Wellbeing in Final Years of Life project aims to develop a better understanding of how best to promote positive MWB in the oldest-old population. Using a resources approach, the present study aimed to provide empirical evidence about the structure of MWB in the $80+$ year age group and to compare this with the structure of MWB in the old (65-79 years) and adult (18-64 years) population. Twenty-eight items reflecting a focus on positive aspects of MWB were selected from the European Social Survey data (24 countries). After application of an exploratory approach using Exploratory Structural Equation Modelling, five- and six-factor model solutions were found to be statistically appropriate, and the results are consistent with the most widely studied dimensions of MWB. Despite specific differences in the factor models and item loadings, evaluation of formal invariance showed that dimensions built in the same way are comparable across age groups. Although explorative and not conclusive, the results of this study contribute insights into the multidimensional structure of MWB in the oldest-old population and provide a starting point for further research on promoting MWB in the later stages of life.
\end{abstract}

Keywords Mental wellbeing $\cdot$ ESEM $\cdot$ Oldest old $\cdot$ Psychological wellbeing $\cdot$ European Social Survey

Valeria Donisi and Federico Tedeschi have contributed equally to this work.

Disclaimer: The ESS ERIC, Core Scientific Team (CST) and the producers bear no responsibility for the uses of the ESS data, or for interpretations or inferences based on these uses. The responsibility for all conclusions drawn from the data lies entirely with the authors.

Electronic supplementary material The online version of this article (https://doi.org/10.1007/s 1090 2-020-00292-y) contains supplementary material, which is available to authorized users.

Jorid Kalseth

Jorid.Kalseth@sintef.no

Extended author information available on the last page of the article 


\section{Introduction}

Europe's population is ageing, and the number of people characterized as 'oldest old' is projected to increase to more than 66.1 million by 2080 (Eurostat 2017). This demographic transition also includes an increased life expectancy at the age of 80 years, which has increased from 8.4 years in 2004 to 9.5 years in 2014 (Eurostat 2016). Although undoubtedly a positive outcome and a reflection of improvements in medical treatment, preventive measures and education levels, this demographic transition also brings new challenges for health-care services, public health and policy development (Cresswell-Smith et al. 2019; Jaul and Barron 2017; Beard et al. 2015; Cohen-Mansfield et al. 2013).

Given these demographic changes, a resource-focused approach that places greater attention on mental well-being (MWB) may be beneficial. Although important in its own right, higher MWB is associated with better physical health and longevity (Boccardi and Boccardi 2019; Chei et al. 2018; Steptoe et al. 2015; Cherry et al. 2013; Diener and Chan 2011; Chida and Steptoe 2008; Smith et al. 2002) and this shift in focus would support actions and initiatives that promote MWB while addressing illness and disability (Cresswell-Smith et al. 2019; Delle Fave et al. 2018; Cosco et al. 2017; Cantarella et al. 2017; Huppert and So 2013). Promoting MWB in older age has potential public health and cost benefits, including decreased burden on older people themselves, their caregivers and health-care professionals (Cosco et al. 2017). Both the World Health Organization (WHO) and the European Commission have highlighted the need for the promotion of mental health and well-being in all stages of life (Lara et al. 2019; European Union 2016; World Health Organization 2013). Although widely recognized as an emerging priority, defining and measuring MWB is not without its difficulties and often includes overlapping concepts and inconsistencies. Several conceptualizations have been proposed, and there is general agreement around MWB as a broad, complex and multidimensional concept (Lara et al. 2019; Linton et al. 2016; Salvador-Carulla et al. 2014; Huppert and So 2013; Nyqvist et al. 2013; Poon and Cohen-Mansfield 2011). Many of these conceptualizations include dimensions such as the evaluative dimension, which refers to overall satisfaction with life (Diener et al.1985; Cantril 1965); the hedonic dimension, which includes aspects such as positive and negative affect (Kahneman et al. 2004); and the eudemonic dimension (Ryff et al. 2004), which relates to the realization of human potential and psychological functioning.

Different authors articulate these aspects of MWB further. Ryff and collaborators have proposed six dimensions of positive psychological well-being: self-acceptance, personal growth, purpose in life, environmental mastery, autonomy and positive relations (Ryff and Keyes 1995; Ryff 1989). MWB has also been associated with the concept of flourishing, which is defined as 'a state in which all aspects of a person's life are good' (VanderWeele 2017) and, according to Seligman (2011), comprises positive emotion, engagement, relationships, meaning and accomplishment (abbreviated using the acronym PERMA). Elements such as optimism and contributing to the well-being of others (Diener et al. 2010) as well as emotional stability and vitality (Huppert and So 2013) are considered to be important facets of MWB. Keyes and collaborators have proposed a social model (Keyes 1998) that emphasizes both psychological and social capacity as important aspects of MWB. This model considers the social world of the individual when assessing MWB (Keyes et al. 2002) and, therefore, shifts the focus from MWB as a private phenomenon to also include a public aspect. It is therefore important to acknowledge that although several important dimensions have been proposed, no clear definition of MWB has been established. 
Research on MWB in the oldest old is especially challenging because of the lack of consistency in definition and measurement of MWB, the heterogeneous nature of older adults, and the general scarcity of research specific to this age group (Lara et al. 2019; Douma et al. 2017; Miret et al. 2015; Hansen and Slagsvold 2012; Poon and CohenMansfield 2011). Although the definitions of oldest-old age vary, this paper defines oldest old as age 80 years and over, as in previous work in this research field (e.g. Lara et al. 2019; Wang et al. 2019; Ng et al. 2017; Andersen-Ranberg et al. 2005). Changes occurring during old age can affect MWB. For example, older people may lose their independence because of physical or cognitive impairment, experience health challenges, lose close relationships (e.g. death of a spouse/partner) or face relocation to new contexts (Smith et al. 2002). Despite these challenges, empirical data indicate a paradox of higher subjective well-being in older groups compared to younger groups, despite the lower objective quality of life (Steptoe et al. 2015). Research across age groups often ignores the multidimensionality of well-being concepts and instead focuses only on one aspect such as life satisfaction (Hansen and Slagsvold 2012). Exploring the intricacies and multidimensionality of MWB across the life-course allows for age differences to be captured and for important elements of MWB to be isolated in different age groups.

Huppert (2014) describes the use of a factorial structure as helpful for exploring the construct of MWB, particularly when studying different demographic groups and countries. Although not focusing specifically on the MWB of the oldest old, Burns (2019) used confirmatory factor analysis to explore well-being across age groups and found that different dimensions of well-being contributed with different factor loadings to an overall latent well-being factor across age groups, even if the effect of these agerelated differences on such factor score was negligible. An exploratory structural equation modelling (ESEM) approach has been reported to be useful for exploring multidimensional constructs such as MWB (Joshanloo 2016).

Improving MWB in the oldest-old age group requires a better awareness of its fundamental components in order to understand its many drivers in later life (Huppert 2009). Aiming to develop a better understanding on how to promote positive MWB in the oldest-old population, the European Welfare Models and Mental Wellbeing in Final Years of Life (EMMY) project (www.emmyproject.eu) adopted a mixed-methods approach. Based on data from 117 participants aged 80 years and over from all four partner countries (Finland, Italy, Norway, Spain), the qualitative component of the study confirmed the multidimensional nature of MWB in oldest old. The study also found that being healthy, having significant social relationships and engaging in productive and inspiring activities are important determinants for MWB in later life (Lara et al. 2019). The present study, framed by EMMY project objectives, used an exploratory ESEM approach to explore the structure of MWB in the oldest old $(80+$ age group) in Europe. A secondary aim was to compare the dimensions of MWB in the $80+$ population with those of other age groups ("old" aged 65-79 years and "adults" aged 18-64 years), both descriptively and by evaluating measurement invariance.

This exploratory approach develops the understanding of MWB in the oldest old by answering the following questions: (1a) Is the multidimensionality of MWB confirmed in the $80+$ age group? (1b) How many factors, and which dimensions characterize MWB in this age group? (2) Can the same model be applied to all age groups, and therefore enable comparisons of the dimensions across age groups? 


\section{Methods}

\subsection{Source of Data and Variables}

The present study used Round 6 European Social Survey (ESS) survey data (2012), which encompasses a broad range of items related to MWB. ESS data stems from face-to-face interviews which adopt robust translation and anonymity protocols (https://www.europ eansocialsurvey.org/data/conditions_of_use.html) and includes strict random probability sampling with a minimum target response rate of $70 \%$. The ESS has been conducted in nine rounds since its establishment in 2001 and comprises core modules that include themes such as Subjective well-being and rotating modules. Round 6 included a rotating module on Personal and social well-being. To increase comparability, the current study included ESS data from the 24 countries belonging to either the European Union or the European Free Trade Association (see Table S1 in the Appendix).

We used a two-step process to select items for the current analysis. In the first step, 47 potentially relevant items from the ESS database representing the different aspects of well-being described above, including evaluative, hedonic, eudemonic, relational and social aspects, were selected by two senior researchers. Most of these items were derived from the Subjective well-being and Personal and social well-being modules. We also added items representing social trust from the Media and Social trust module, and the life satisfaction item from the Politics module (Jeffrey et al. 2015). Three items connected to physical health were excluded because we focused specifically on MWB dimensions.

Following this initial selection, an expert panel independently revised the list of the MWB items to be included in the analysis. The panel comprised nine EMMY team members from European countries (Italy, Norway, Spain, Finland) representing different disciplines (clinical psychology, social psychology, social science, psychiatry), and included experts in the well-being field. The panel was asked to a) indicate which items should be included; b) place the items into different well-being dimensions according to two predefined models (dimensions emerging from the qualitative EMMY study (Lara et al. 2019) and the NEF model of well-being (Michaelson et al. 2009). This assessment resulted in considerable disagreement and variation in linking items and dimensions, a finding that motivated the present study.

The final selection of items was settled by using the majority principle and included items which were supported by at least five experts. These items reflected a focus on positive aspects of MWB, in accordance with the EMMY project framework, which conceptualized MWB not just as the absence of ill-being or disability, but as the presence of positive emotions and functioning (Lara et al. 2019; Cresswell-Smith et al. 2019). In line with this, all negatively worded items (about affect, functioning or vitality) and items related to social trust, social growth and safety were excluded. A final list comprising 28 items was considered for the analysis of MWB (see Table S2 in the Appendix). The selected items corresponded well with previous studies such as Tennant et al. (2007) in relation to the Warwick-Edinburgh Mental Well-Being Scale (WEMWBS), which includes only positively worded items relating to aspects of positive mental health such as the concepts of positive affect, psychological functioning and interpersonal relationships. 


\subsection{Statistical Analysis}

\subsubsection{Descriptive Analysis}

The ESS sample was divided into three subsamples according to the following age stratification: adult population (aged 18-64 years), old (65-79 years) and oldest old $(80+$ years $)$. These three age groups can generally be considered to represent differing needs. The 18-64 age group may be assumed to represent the adult population in general, whereas the 65-79 age group represents a predominantly retired population who may have some health and social needs, although these are likely to be fewer than those for the oldest-old group. The oldest old group aged 80 years and over is typically at increased risk of physical illness, comorbidities and need for social and services support (Smith et al. 2002). For each ESS well-being item, the mean value, standard deviation (SD) and range were calculated for each age group. In the case of the oldest old, the correlation matrix has been calculated as well.

\subsubsection{Factor Analysis}

To analyze the number of MWB dimensions, an exploratory factor analysis (EFA) (Brown 2015) was initially performed on the $80+$ group. This was accompanied by a parallel analysis (Horn 1965; Costello and Osborne 2005) and the Kaiser criterion (Kaiser 1960) of initial eigenvalues above 1. To define the MWB dimensions, the ESEM approach (Asparouhov and Muthén 2009) was used, based on the methodological findings from previous studies, which found that ESEM provided a better fit than confirmatory factor analysis (CFA) because ESEM allows for item cross-loadings (Joshanloo 2016; Marsh et al. 2014). Maximum likelihood estimation with robust standard errors was performed, followed by oblique geomin rotation. Missing data were handled using full information maximum likelihood (Enders 2010). Results from the ESEM were described in terms of interpretability and correlations between factors. The relevance of items was also assessed in terms of statistical significance (i.e., factor loading $t$ ratio $\geq 1.96$, Wang and Wang 2012). To ensure that all items followed the same direction (i.e. positively related to well-being), the scale of eight items was reversed (see Table S2 in the Appendix) when performing the ESEM analyses.

The fit of all models was evaluated using several criteria (Hu and Bentler 1999; Brown 2015; Kline 2016): the comparative fit index (CFI $\geq .95$ good, $\geq .90$ acceptable); Tucker-Lewis index (TLI $\geq .95$ good, $\geq .90$ acceptable); root-mean-square error of approximation (RMSEA $\leq .06$ good, $\leq .08$ acceptable) with its $90 \%$ confidence interval; and the standardized root-mean-square residual (SRMR $\leq .08$ good, $\leq .10$ acceptable).

Construct reliability of each factor was assessed using Cronbach's alpha; for each factor, the items with the highest factor loadings in the ESEM were used. All analyses were conducted using Mplus version 7.2 (Muthén and Muthén 2012) with standardized solutions: both items and factors were standardized to have null mean and unit variance. Given our focus on factor structure and not on descriptive statistics, we used unweighted observations because the use of weights would have made results strongly dependent on observations of under-represented groups, which would likely reduce the efficiency of the estimates (Gelman 2007; Winship and Radbill 1994). 
There is no generally accepted rule-of-thumb regarding evaluating the size of factor loadings because their values can depend on, for example, how conceptually close the item is to the latent variable (factor). As the sample size and number of items being analyzed increase, the acceptable level for considering a loading decreases significantly (Hair et al.1998). A cut-off of .30 has been used to describe the factor loadings and to define low factor loading (for ESS data, Charalampi et al. 2018; Brown 2015; Kim and Mueller 1978).

\subsubsection{Invariance Analysis}

To measure the invariance of the dimensions (Vandenberg and Lance 2000; Meredith 1993) across age groups, we performed an evaluation using multigroup modelling and a strategy involving three steps in a nested structure (Marsh et al. 2009). First, we analyzed the configural invariance by implementing multigroup ESEM in which all parameters were freely estimated across all groups. Second, the weak (or metric) measurement invariance was analyzed (Horn and McArdle 1992) and third, we analyzed strong (or scalar) measurement invariance. Invariance was evaluated initially by comparing the dimensions of the three groups simultaneously and by then comparing the $80+$ group with the other two age groups separately: $80+$ versus $65-79$ age groups and $80+$ versus 18-64 age groups. The oldest-old group was used as the reference group. In the case of lack of invariance, the parameters of the models were compared across groups.

Changes in the CFI $(\Delta \mathrm{CFI})$, TLI $(\Delta \mathrm{TLI})$ and RMSEA ( $\triangle$ RMSEA) were considered to assess invariance. In particular, the values for $\Delta$ CFI, $\Delta$ TLI $<-.01$ by Cheung and Rensvold (2002) and Rutkowski and Svetina (2014), and $\Delta$ RMSEA > .015 (Chen 2007) were used as indicators of significant difference between two nested models in regard to model fit: the hypothesis of invariance was rejected if it implied a relevant worsening of the model fit. As a final assessment of the goodness of fit in the measurement invariance model, we calculated the correlations between factor scores from the ESEM analysis for the $80+$ group alone with the corresponding factor scores resulting from the scalar invariance model.

\section{Results}

\subsection{Descriptive Results}

Our inclusion criteria resulted in a dataset comprising 43,567 people: $33,163(76.1 \%)$ aged 18-64 years, $8346(19.2 \%)$ aged 65-79 years and $2058(4.7 \%)$ aged $80+$ years. The average age of the $80+$ age group was 84.1 years (SD 3.67) and the oldest was 103 years. The average ages were 71.1 years (SD 4.18) in the 65-79 age group and 42.5 years (SD 13.2) in the 18-64 age group. Most participants were women in all three age groups, and the gender imbalance increased with age at the moment of the survey (see Table S3 in the Appendix). Table S2 in the Appendix shows the results across the 28 MWB items and the list of the original 47 items. Table S8 and Figure S1 in the Appendix show the between-item correlation matrix and the related heat-map. 
Table 1 Summary of Goodness-of-Fit Statistics for the three age groups with MLR

\begin{tabular}{lrllllll}
\hline EFA model & MLR $\chi^{2}$ & df & CFI & TLI & RMSEA & CI 90\% & SRMR \\
\hline 80+ group & & & & & & & \\
5-factor & 1363.782 & 248 & 0.937 & 0.903 & 0.047 & $0.044-0.049$ & 0.026 \\
$\begin{array}{l}\text { 6-factor } \\
\text { 18-64 group }\end{array}$ & 873.551 & 225 & 0.963 & 0.938 & 0.037 & $0.035-0.040$ & 0.021 \\
5-factor & $15,527.207$ & 248 & 0.938 & 0.905 & 0.043 & $0.043-0.044$ & 0.027 \\
6-factor & $10,982.905$ & 225 & 0.956 & 0.926 & 0.038 & $0.037-0.039$ & 0.020 \\
65-79 group & & & & & & & \\
5-factor & 4348.124 & 248 & 0.941 & 0.910 & 0.045 & $0.043-0.046$ & 0.027 \\
6-factor & 2983.703 & 225 & 0.960 & 0.933 & 0.038 & $0.037-0.040$ & 0.020 \\
\hline
\end{tabular}

$C F I$ comparative fit index, TLI Tucker-Lewis index, $d f$ degrees of freedom, RMSEA root-mean-square error of approximation, SRMR standardized root mean square residual, MLR maximum likelihood robust, EFA exploratory factor model, $C I$ confidence interval

\subsection{Analysis of the Dimensional Structure of MWB Within the $80+$ Age Group}

Table 1 shows the most parsimonious solutions, including 5-6 factors, with acceptable fit indices for the $80+$ age group. Both the parallel analysis and the Kaiser criterion suggested a five-factor solution for the oldest-old group, and this solution also fulfilled the criteria for acceptable fit $(\mathrm{CFI} / \mathrm{TLI}>.90$, RMSEA/SRMR <.08). However, the 95 limit for CFI was met only for a solution involving $\geq 6$ factors, which implied that both models were acceptable.

Table 2 reports the results of the ESEM for both the five- and six-factor solutions for the $80+$ group.

In the five-factor model, examination of the factor loadings showed that MWB factors corresponded to (i) evaluative and emotional dimensions of well-being, which included items referring to life satisfaction and evaluation of positive affect such as enjoyment, calmness and happiness; (ii) positive psychological functioning, which included items referring to autonomy, competence, self-esteem, optimism and vitality; (iii) meaning and flow, which included items referring to presence and engagement; (iv) social engagement, which included items referring to being involved in social activities such as volunteering and charitable work, social interactions and learning new things; and (v) positive and supportive relationships, which included items referring to received support and appreciation by others and help and provide support to others.

The six-factor model showed similar dimensions, except that the first factor, evaluative and emotional well-being, was divided into two factors. In this model, 'have a sense of direction in life' had its highest factor loading for the evaluative well-being dimension (although with a loading <.3) and the emotional well-being dimension also included the item about vitality (i.e. 'full of energy') with a factor loading $>.3$.

Most items had loadings $>.3$ on the factor with the highest loading. There were a few exceptions: items 'have a sense of direction in life', 'take notice and appreciate surroundings', 'deal with important problems in life' and 'feel close to the people in local area'.

Only one item, 'always optimistic about my future', had a loading $>.3$ on more than one factor: it cross-loaded on evaluative well-being and positive psychological functioning dimensions (in both the five- and six-factor models); the highest loading was on the latter. 


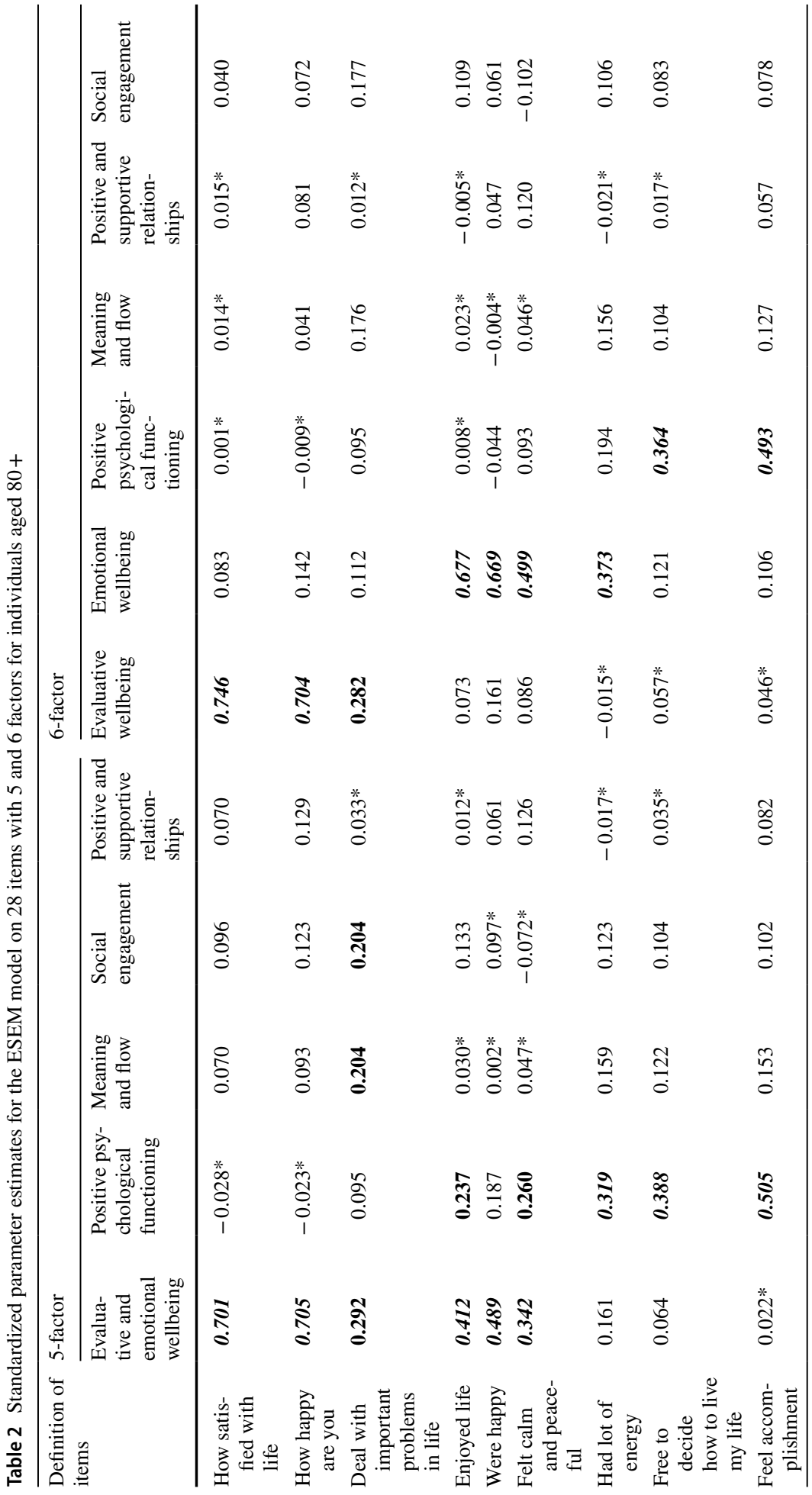




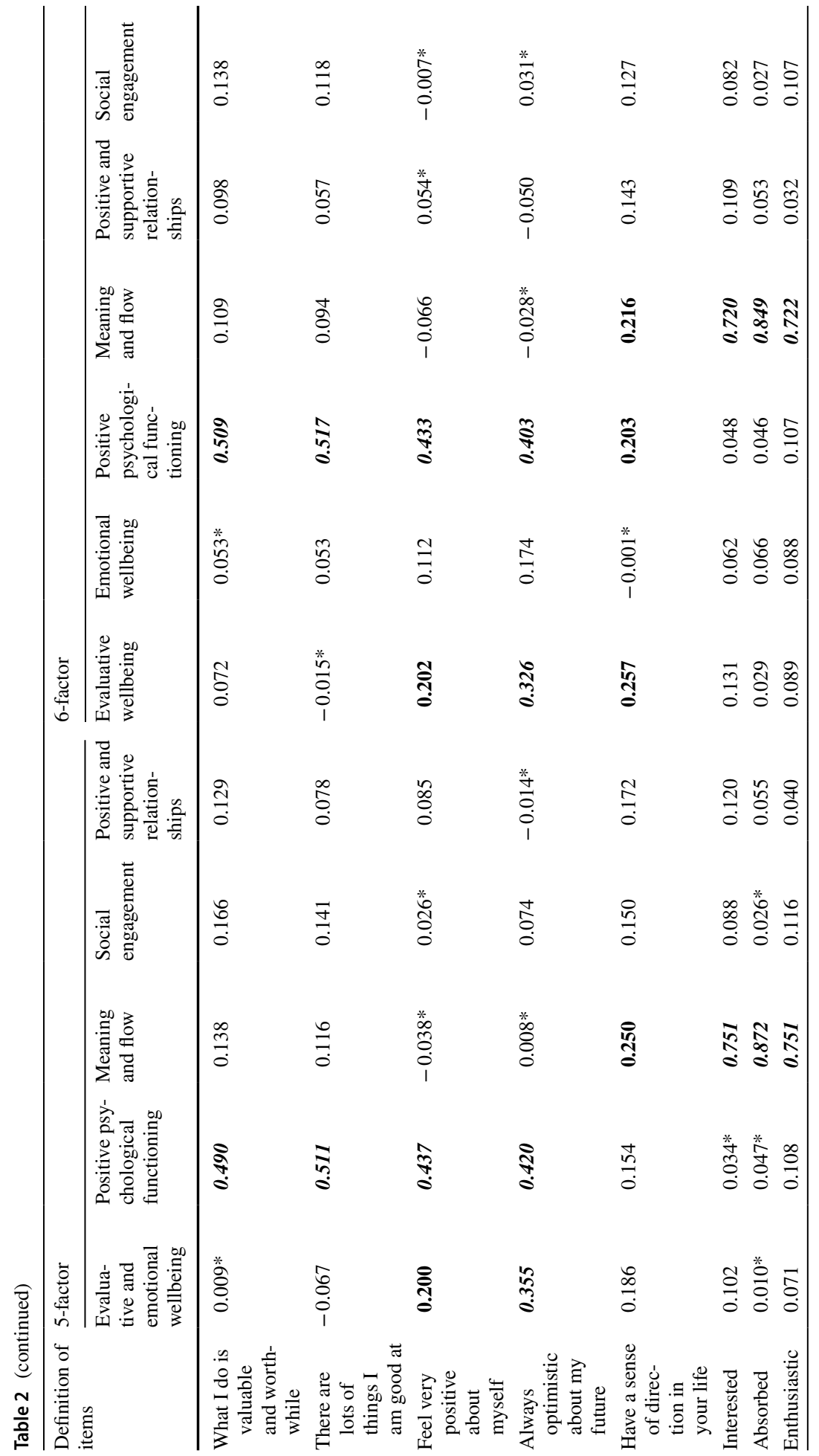




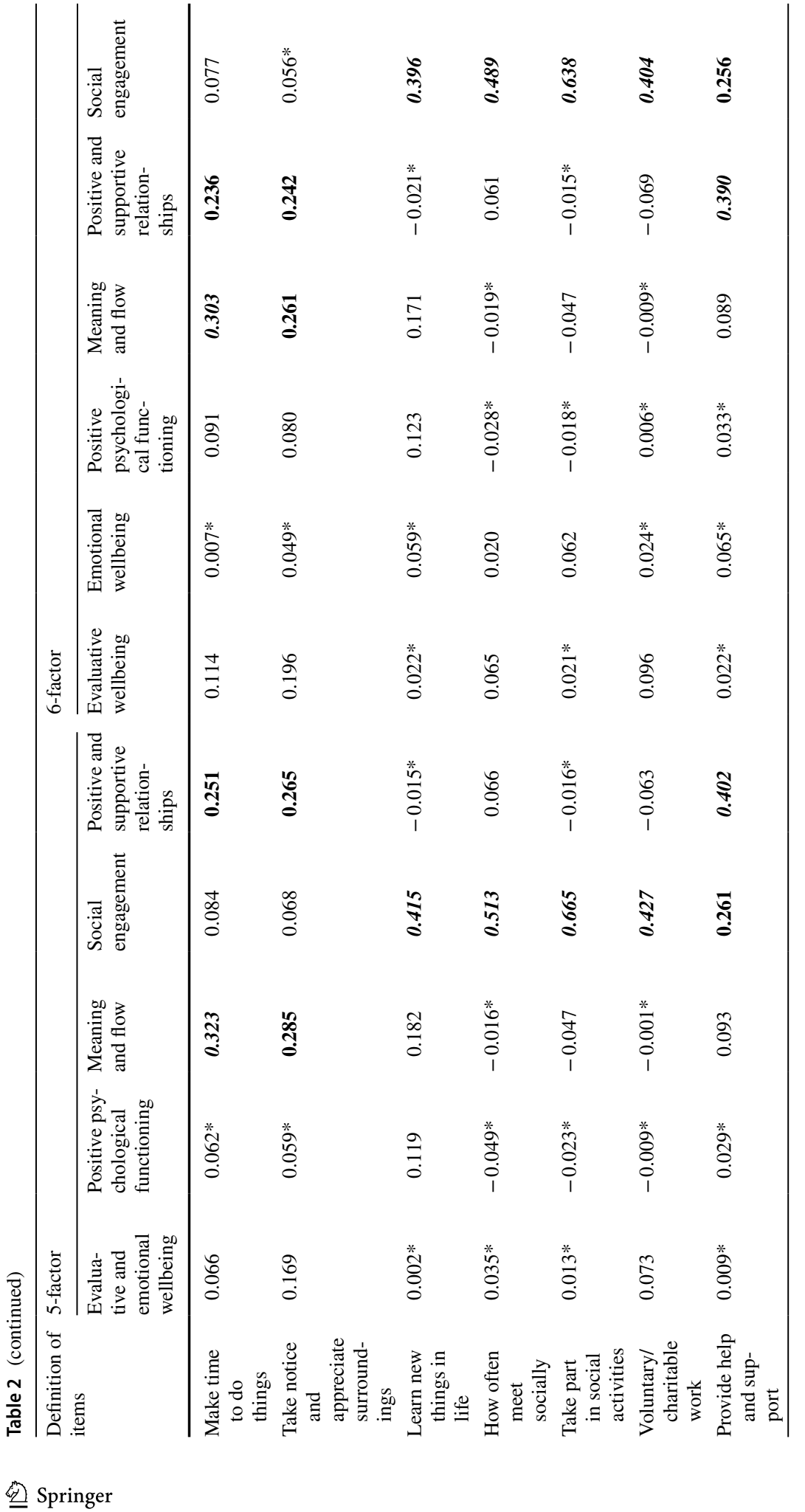




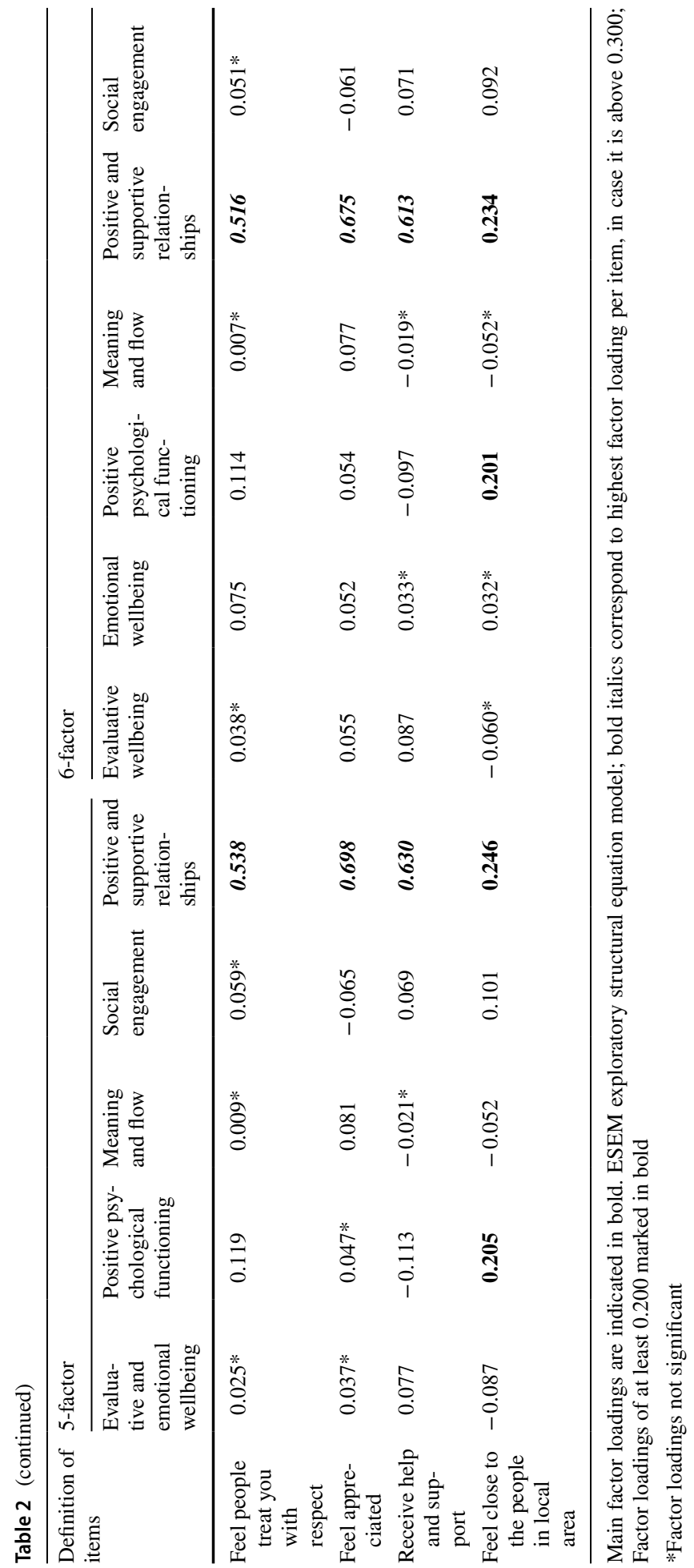


Some items such as 'have lots of energy', 'provide help and support' and 'make time to do things' had a difference of $<.2$ between the highest and second-highest factor loadings both in the five- and six-factor solutions. Finally, for all factors, the number of items with factor loading $>.5$ was between 1 and 3 .

The construct reliability of the factors/dimensions as measured by Cronbach's alpha were as follows: .823 for evaluative and emotional well-being in the five-factor solution; .781 for evaluative well-being and .757 for emotional well-being in the six-factor solution; .802 (five-factor solution) and .791 (six-factor solution) for positive psychological functioning; .869 (five-factor solution) and .865 (six-factor solution) for the meaning and flow dimension, .601 (both five- and six-factor solutions) for the social engagement dimension; and .692 (both five- and six-factor solutions) for positive and supportive relationship well-being.

Interfactor correlation matrices are reported in Table 3. Correlation coefficients were always $<.4$ in the five-factor solution, supporting the interpretation of the factors as separate constructs. In the six-factor model, the highest correlation coefficient (.47), and the only one >.4, was between evaluative and emotional well-being.

\subsection{MWB: Descriptive Differences Across Age Groups}

Using the EFA analysis and the same criteria used for the 80 + group (Table 1), a five-factor solution was found to be acceptable for the 18-64 and the 65-79 age groups, although the parallel analysis suggested that the six-factor solution was more appropriate for the adult population (18-64 age group). Based on the highest factor loadings for both the fiveand six-factor models, the ESEM results for the 18-64 and 65-79 age groups were similar in terms of structure (see Tables S4 and S6 in the Appendix).

The five-factor model for the 18-64 age group and 65-79 age group showed similarities to the $80+$ age group on three factors: positive psychological functioning, meaning and flow, and positive and supportive relationship. Conversely, the first two factors corresponded to those in the six-factor solution for the $80+$ age group, and distinguished between evaluative well-being and emotional well-being. Hence, the social engagement dimension (fourth factor of the five-factor model for the $80+$ group) was not found in the five-factor solution for the 18-64 and 65-79 age groups. Items included in this factor in the six-factor solution did not load on other factors in the five-factor case. Also, in the case of the $80+$ group, such items showed weak associations (factor loadings always $<.3$ ) with the

Table 3 Factor correlation matrix: 5- and 6-factor solutions

\begin{tabular}{|c|c|c|c|c|c|c|c|c|c|c|c|c|}
\hline \multirow[t]{2}{*}{ Factor } & \multicolumn{5}{|c|}{ 5-factors model } & \multirow[t]{2}{*}{ Factor } & \multicolumn{6}{|c|}{ 6-factors model } \\
\hline & 1 & 2 & 3 & 4 & 5 & & 1 & 2 & 3 & 4 & 5 & 6 \\
\hline 1 & 1.000 & & & & & 1 & 1.000 & & & & & \\
\hline 2 & 0.393 & 1.000 & & & & 2 & 0.466 & 1.000 & & & & \\
\hline 3 & 0.319 & 0.374 & 1.000 & & & 3 & 0.332 & 0.360 & 1.000 & & & \\
\hline 4 & 0.350 & 0.350 & 0.344 & 1.000 & & 4 & 0.329 & 0.269 & 0.358 & 1.000 & & \\
\hline 5 & 0.295 & 0.281 & 0.352 & 0.261 & 1.000 & 5 & 0.288 & 0.230 & 0.248 & 0.309 & 1.000 & \\
\hline & & & & & & 6 & 0.321 & 0.290 & 0.302 & 0.297 & 0.207 & 1.000 \\
\hline
\end{tabular}

All correlations are significant $(p<0.001)$ 
other factors, which indicated that these aspects were not core parts of other dimensions either.

Overall, the six-factor solution indicated a separate factor for social engagement for all age groups. However, the 'learn new things' and 'voluntary work' items weakened with younger age at the time of the survey. 'Learn new things' had a factor loading of $<.3$ for both the 18-64 and 65-79 age groups, and 'voluntary work' had a factor loading of $<.3$ in the 18-64 age group. In addition, the item 'feel people treat you with respect' loaded at $<.3$ on the positive and supportive relationship dimension for the 18-64 age group.

As in the case of the $80+$, interfactor correlations for the other age groups were low in both models, which indicated that the factors may be interpreted as separate constructs (see Tables S5 and S7 in the Appendix).

\subsection{Measurement Invariance Between the 80+ and 65-79 Age groups and Between the 80+ and 18-64 Age groups}

Invariance across age groups was formally tested for the six-factor model because of its higher comparability across groups. Table 4 shows the results from the multigroup ESEM approach used to analyze invariance for the six-factor solution.

A multigroup model with no constraints on factor loadings was used to analyze configural invariance (model 1 (M1)), a multigroup model with invariant factor loadings across the two groups was used to analyze metric invariance (M2), and a multigroup model with invariant factor loadings and item intercepts was used to analyze scalar invariance (M3). All models provided acceptable CFI, TLI and RMSEA values. The multigroup model M1 provided a good fit $(\mathrm{CFI}>.95$, TLI $>.90$, RMSEA <.05) for both age group comparisons (18-64 vs. $80+$ and $65-79$ vs. $80+$ ), thus supporting configural invariance.

Table 4 shows that the M2 model had better or comparable model fit indices than M1, whereas the fit for M3 did not decrease significantly compared with M2, with both M2 and M3 performing even better than M1. Such results suggest the presence of both scalar and metric invariance, which indicates that the factor loadings and item intercepts may be considered as stable across groups.

We found similar results for invariance for the five-factor model (data not shown).

The correlation coefficients between the corresponding factor scores of the models assuming and not assuming measurement invariance were .992 for evaluative well-being, .987 for emotional well-being, .972 for positive psychological functioning, .990 for meaning and flow, .966 for positive and supportive relationships and .959 for social engagement. This indicates that, in case we assume measurement invariance, the information conveyed by factor scores basically remains the same.

\section{Discussion}

\subsection{MWB Factors in the Oldest Old}

The resource-based approach employed in the EMMY project highlighted the need to focus on positive aspects of MWB in oldest old age (Lara et al. 2019; Cresswell-Smith et al. 2019). This approach is also consistent with theoretical models emphasizing positive MWB such as those underlying the Seligman's PERMA model (Seligman 2011), WEMWBS (Tennant et al. 2007) and WHO-5 Well-Being Index (Topp et al. 2015). Using 28 


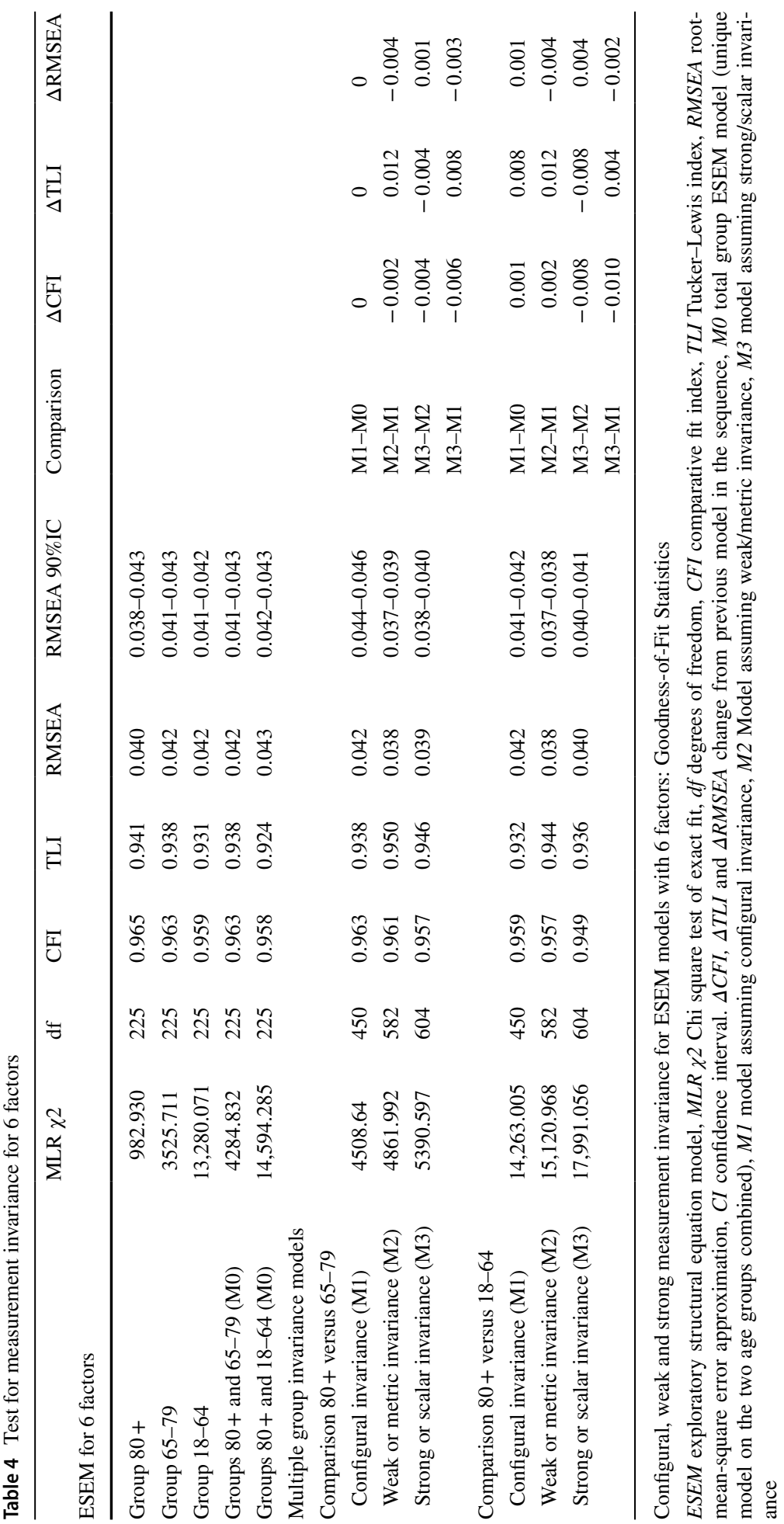


items from the large ESS to empirically analyze the dimensions of MWB in the oldest-old group, our study results support the consideration of MWB as a multifaceted construct also in this age group.

We found that MWB in the oldest-old group could be represented by a five-factor model that included the following five dimensions: evaluative and emotional well-being, positive psychological functioning, meaning and flow, social engagement, positive and supportive relationships. However, our results also supported a six-factor model in which evaluative well-being and emotional well-being represented separate dimensions. Both solutions were statistically appropriate and theoretically interpretable, and our results are consistent with the most widely studied dimensions of MWB. Although most of items did not show strong factor loadings, the low intercorrelation values indicated that the interpretation of factors was not hampered by interfactor correlations, suggesting that the included dimensions measured different aspects of MWB.

\subsection{Comparison of MWB Factors between $80+$ and Other Age Groups}

Our second aim was to explore the differences between the oldest-old and the two younger age groups, the adult population (aged 18-64 years) and the old population (aged 65-79 years). Although a five-factor model was found to be generally acceptable, the sixfactor model appeared to be more appropriate for the two younger groups, namely the adult and old age groups.

For these two age groups, the evaluative and emotional well-being dimensions represented separate factors even in the five-factor solution. This finding suggests that, as noted by Vanhoutte (2014), a higher level of information may be reached by distinguishing between such aspects of well-being; however, the same result was not found in the fivefactor solution for the oldest-old group.

Comparison of the matrices of factor correlations in the six-factor solutions (Table 3 and Table S7 in the Appendix) offers an explanation for such different results across age groups, by showing that in the oldest old group, i.e. 80 years and over, these two dimensions had a more similar correlation with positive and supportive relationships and social engagement than in the two younger age groups, for which the correlation coefficients for evaluative well-being were considerably higher than those for emotional well-being.

Our results suggest that the separation of cognitive and affective evaluations of life, which represent distinct dimensions of MWB (Diener et al.1999), was stronger in the younger age groups than for the oldest old. Life satisfaction may vary according to expectations and relevant goals (Berg et al. 2006; Diener and Fujita, 1995). The stronger relationship between evaluative and emotional well-being in oldest old age may be explained by the socioemotional selectivity theory, which states that the perceived limitation in time directs increased attention to emotionally meaningful goals in older age (Carstensen et al. 2003; Carstensen1992). Therefore, it seems plausible that in the oldest old, evaluations of life satisfaction are made in connection to recent positive experiences and recent positive affect.

Similarly, judging by the factor loading on the vitality item 'had lots of energy' in the emotional well-being dimension decreasing with age at the moment of the survey, it seems that having lots of energy is more important for emotional well-being for younger people than for the oldest old.

The separation of evaluative and emotional well-being in the five-factor model among the two younger age groups seemed to have occurred at the expense of the social 
engagement dimension, because all items connected to this dimension had low loadings on all factors in the 18-64 and 65-79 age groups. On the other hand, the six-factor model produced a more similar factor structure for all age groups, since a separate dimension for social engagement also emerged for the younger age groups, even though some items had low factor loadings.

The loading of items for the two social dimensions (social engagement and positive and supportive relationships) appears to be more age sensitive than for items in the other MWB dimensions. The loadings of items 'provide help and support', 'receive help and support' and 'meet socially' decreased with age at the moment of the survey, to indicate a lower relevance of these items on the social dimensions for the $80+$, whereas the opposite was found for 'feeling respected' and 'feeling appreciated'. This might suggest that, although similar items contribute to the same social dimensions of MWB, some aspects can be more or less relevant at different stages of life. Specifically, for the $80+$ age group a major contribution to social dimensions of MWB is given by positive feelings in relation to others, rather than on social behavior (i.e. meet others, give/receive support). This is coherent with the fact that, as noted by Keyes (1998), the importance of each aspect of social wellbeing may vary with age in diverse ways, i.e.: "some aspects of social well-being decrease linearly; others increase linearly; still others increase, but at a decelerating rate".

However, we note that the reliability of the social dimensions was low, as indicated by the Cronbach's alpha values for both the five- and six-factor solutions for the oldest old. A possible explanation is that the available items did not allow for a valid or reliable enough estimate of such dimensions, because both items relating to feelings and items more quantitative in nature are included. As regards this discussion, Larson (1996) argued that only items capturing internal responses to the social environment ("feelings, thoughts and behaviors reflecting satisfaction or lack of satisfaction with the social environment") such as those relating to adequate adjustment, functioning and interaction, as judged by the individual, can be part of an individual's (mental) health. This view implies that items capturing interpersonal comparisons which are more quantitative in nature, such as questions around 'how often/many ... (compared with others)' are not in line with a good measure of social aspects of wellbeing. Suffice to say that both categories are represented among items in the social dimensions. Furthermore, although positive relationships with others are typically seen as part of psychological well-being (Ryff and Singer 2008) they could also be viewed as part of social well-being (Gallagher et al. 2009). Other aspects of social well-being are often not included in analyses of the construct of well-being (e.g. Vanhoutte 2014). Mental and social well-being may be seen as closely interrelated but distinct concepts (e.g. Van Lente et al. 2012) and one could question whether items relating to social well-being should be included in an MWB analysis. With reference to Larson's (1996) line of reasoning, Keyes (2002) argued for inclusion of social wellbeing in conceptualization of mental health (flourishing). Further research is needed to deepen the understanding of the role and the structure of social engagement and positive and supportive relationships dimensions in relation to MWB across ages and in the oldest-old population.

\subsection{Cross-Loadings of Individual Items}

As regards MWB for the $80+$ age group, cross-loadings for individual items emerged in both the five- and six-factor models. The Cronbach's alpha values for the meaning and flow and positive psychological functioning factors indicated that each group of items may be part of only one specific dimension of MWB. However, despite the global reliability of 
these dimensions, when looking at single items, some had low factor loadings and were cross-loaded with other dimensions. Restricting the MWB model to five factors for the oldest old age group appeared to force higher cross-loading with positive psychological wellbeing factors for some items which were associated with only one of the evaluative and emotional aspects of MWB such as the 'lots of energy', 'direction in life', 'enjoyed life', 'calm and peaceful' and 'were happy' items.

Furthermore, cross loadings were also found in relation to aspects connected to adaptation, emotional regulation and resilience, all of which can be considered to be important drivers of positive MWB (Cosco et al. 2017; Hansen and Slagsvold 2012) along with factors relating to general disposition and personality (Enkvist et al. 2012). Items such as 'feel very positive about myself' and 'always optimistic about my future' loaded highest in terms of the positive psychological functioning dimension, but they also cross-loaded on evaluative well-being. In the six-factor model, 'have a sense of direction in life' had a nonnegligible loading $(>0.2)$ on three factors: evaluative well-being, positive psychological functioning and meaning and flow. Cross-loading was also found between psychological and social dimensions such as 'make time to do things', 'notice and appreciate surroundings' and 'feel close to people in local area'.

The 'provide help and support' item, which was part of the positive and supportive relationship dimension, had a factor loading of just $<.3$ on the social engagement dimension. This indicated that, for the oldest-old age group, providing help and support to others may be relevant for MWB both in terms of the social network dimension and the social engagement dimension. 'Providing help and support' to others was found to be associated with the feelings of belonging, appreciation and respect, as was the opportunity to engage socially through voluntary or charitable contributions and learning new things. This finding supports results from previous studies highlighting the importance of helping and supporting others for well-being (Brown et al. 2013; Dunn et al. 2008) and may relate to the experience of meaningfulness in life among the oldest old. This echoes other findings showing that both participation in meaningful activities (Bryant et al. 2001) and social connectedness (Forsman et al. 2013; Bowling and Gabriel 2007) are crucial to MWB in later life. In particular, social activities seem to offer structure and meaning in the everyday lives of older adults (Forsman et al. 2013; Bowling and Gabriel 2007), therefore increased opportunities for participating in social activities (both formal and informal) may help to sustain their MWB and prevent loneliness (Forsman et al. 2013). Also noteworthy is a qualitative study conducted in Norway which reported that regular contact with family and neighbors was a prerequisite for good well-being in the oldest old (Granerud et al. 2017). This reflects other findings emphasizing social context, social interaction and participation as key components of MWB (Tomini et al. 2016; Nyqvist et al. 2013).

Some of the cross-loadings were only observed in the oldest old group, e.g. 'provide help and support', while others, e.g. 'direction in life' emerged in all groups.

These results support the results of Joshanloo (2016), who found significant cross-loadings between MWB factors.

\subsection{Invariance Analysis}

Despite the differences described above, the evaluation of formal invariance showed that dimensions built in the same way are comparable across groups. This has methodological benefits by indicating that MWB is comparable and differences between average values on well-being dimensions can be analyzed. These findings parallel those of Burns (2019), 
who used data from 2006 to study age-related differences in the factor structure of multiple wellbeing indicators. The results may be better understood in light of the very high correlation between corresponding factor scores in the models that did and did not assume metric invariance. This finding suggests that if metric invariance is assumed, the results change only very slightly for the social dimensions and even negligibly for the other factors. Therefore, as the differences in the factor composition did not have a relevant effect on factor scores, our results do not support the need for specific instruments for the oldest old.

\subsection{Strengths and Limitations of the Study}

The current study presents some strengths and limitations. Although being able to include multinational data from different European countries was a strength of the current study, not considering the influence of cross-country and/or cross-cultural differences was a limitation. For instance, the qualitative component of the EMMY study found cross-cultural differences in terms of the relevance of relationships for MWB. Participants from Spain and Italy tended to place the focus mainly on interactions with their closest family, whereas people in Nordic countries gave relevance to both informal relationships and formal social participation. Furthermore, the value of autonomy was articulated to a greater extent in the Nordic countries than in Spain and Italy (Lara et al. 2019). Results from the current study provide a starting point for further analysis, including comparisons of the structure of MWB between countries or groups of countries in Europe (e.g. western and eastern countries, Nordic, central or Mediterranean countries) and exploration of the role of different determinants of MWB, such as the welfare system and socio-economic factors which could inform effective approaches for the promotion of MWB.

To our knowledge, our study is the first to use ESEM models to explore MWB in the oldest old age group in Europe and using ESEM instead of CFA is a clear methodological strength. The low reliability of the two social dimensions reinforces the use of ESEM models as it allows for cross-factor loadings to be considered, as items can often be seen to contribute to different factors. Although secondary loadings are often not analyzed in models of MWB with real data, zero secondary loadings are rare (Joshanloo and Weijers 2019).

The objective of our study was to explore the dimensions of MWB in the European population, without considering socio-demographic characteristics (other than age) or comparing countries. Further studies, possibly including larger populations, might analyze subgroups of the oldest-old population or compare different countries or groups of countries. Given the cross-sectional nature of our study, another limitation is that we were unable to evaluate whether differences between age groups were inherent to age or reflected the different life experiences associated with having been born in and having lived through different social and historical periods. Future studies using longitudinal data could evaluate invariance of the dimensions of MWB with respect to time in specific cohorts of the European population. Also, between cohort evaluations could be made, measuring the social and historical circumstances which may have influenced the European population.

Focusing on resources and including a wide range of items focused on positive MWB in the oldest old was of further benefit to the study. Increased focus on positive mental health in later life is important when developing resilience strategies and promoting opportunities for meaningful ageing (Delle Fave et al. 2018; Cosco et al. 2017; Araújo et al. 2017) and many of the included items could be relevant in terms of policy development. It is however important to acknowledge that different conceptualizations and measures of MWB may produce different findings from those presented here. 
The decision to use the ESS database was made due to its size, representativeness and comprehensive coverage of well-being dimensions. However, even though the ESS uses rigorous methods to achieve full coverage of the population and reduce the non-response rate (Lynn et al. 2007), we recognize that the oldest-old age group may be underrepresented as this age group naturally includes a higher percentage of people whose participation in the survey may have been hampered by physical or cognitive illness. Considering that physical health is recognized as a possible determinant of MWB, this potential selection bias may have inadvertently resulted in the data from the oldest-old age group bearing higher similarity to those of the younger age groups. Another limitation may be that the ESS data only includes individuals outside of formal care institutions, which may have led to a further selection bias especially in terms of the oldest-old population. Indeed, the authors recognize that contextual circumstances such as living in a nursing home may impact subjective well-being (Douma et al. 2017).

\section{Conclusion}

The increase in life expectancy and current demographic transition emphasizes the relevance of promoting MWB among all age groups, including the oldest old. Using a large European data base, we were able to empirically analyze the MWB structure, finding support for MWB as a multidimensional construct also in the oldest-old group. This has practical implication, suggesting the relevance to act on different dimensions to improve MWB for oldest old age, including initiatives that build resilience, allow for life-long learning, and safeguard social recognition and respect and personal and social engagement.

Our data suggest that it is acceptable to compare MWB dimensions between the oldestold and younger age groups. However, we also found some characteristics that appeared to be specific to the oldest old age group. For example, in the five-factor model, the social engagement dimension emerged as a factor in the oldest old age group, but not in the younger age groups. The five-factor model also suggested that evaluative and emotional well-being was one dimension in the oldest old age group, which was not found in other age groups. Despite these differences, our results do not support the need for a tool with a specific structure for the oldest old because the differences in the factor composition do not have a relevant effect on factor scores.

Given the limitations mentioned above and the exploratory approach used, our results cannot be considered as conclusive. Nevertheless, they contribute new insights into the structure of MWB for the oldest old age group and may provide a springboard for further research. Because the oldest-old population represents a highly heterogeneous group, differences across subgroups should be considered, accounting for different levels of physical health, functional impairment and contextual factors.

The current study adopted a positive approach to MWB in line with the ethos of the EMMY project, and looked for factors that may contribute to enhancing MWB rather than reducing ill-being. This focus on positive mental health reflects a general trend which moves away from the linear assumption that mental health is merely the absence of mental illness, adhering to the WHO's definition of mental health as 'a state of well-being in which every individual realizes his or her own potential, can cope with the normal stresses of life, can work productively and fruitfully, and is able to make a contribution to her or his community' (WHO 2004). 
Considering the current and future demographic changes, developing resource-based approaches that support MWB in the oldest old age group will become even more pertinent. This has particular importance for researchers, health professionals and policy makers.

Acknowledgements Open Access funding provided by SINTEF AS.

Author Contributions JK coordinated the work package of the EMMY project which served as basis for the development of the study; JK, VD, FT, JLGC, FA conceptualized the study idea; JK and FT were responsible for the data management and preparation; FT and JLGC conceptualized and conducted the statistical analysis; VD, FT, JK, JCS drafted the manuscript; all authors commented for intellectual content and contributed to the drafting of the manuscript. All authors read and approved the final version of the manuscript.

Funding This study was funded by The Joint Programming Initiative (JPI) "More Years, Better Lives- The Potential and Challenges of Demographic Change"; and has received funding by the "Acciones de Programación Conjunta Internacional 2016" program (PCIN-2016-118) of the Spanish Research Agency (AEI) of the Spanish Ministry of Economy, Industry and Competitiveness; the Italian Ministry of Health; the Academy of Finland; and the Research Council of Norway.

\section{Compliance with Ethical Standards}

Conflict of interest The authors declare that they have no conflict of interest.

Open Access This article is licensed under a Creative Commons Attribution 4.0 International License, which permits use, sharing, adaptation, distribution and reproduction in any medium or format, as long as you give appropriate credit to the original author(s) and the source, provide a link to the Creative Commons licence, and indicate if changes were made. The images or other third party material in this article are included in the article's Creative Commons licence, unless indicated otherwise in a credit line to the material. If material is not included in the article's Creative Commons licence and your intended use is not permitted by statutory regulation or exceeds the permitted use, you will need to obtain permission directly from the copyright holder. To view a copy of this licence, visit http://creativecommons.org/licenses/by/4.0/.

\section{References}

Andersen-Ranberg, K., Petersen, I., Robine, J. M., \& Christensen, K. (2005). Who are the oldest old? In A. Börsch-Supan, et al. (Eds.), Health, ageing and retirement in Europe-First results from the survey of health, ageing and retirement in Europe (pp. 35-40). MEA: Springer.

Araújo, L., Ribeiro, O., \& Paúl, C. (2017). Hedonic and eudaimonic well-being in old age through positive psychology studies: A scoping review. Anales de Psicología, 33(3), 568-577. https://doi.org/10.6018/ analesps.33.3.265621.

Asparouhov, T., \& Muthén, B. (2009). Exploratory structural equation modeling. Structural Equation Modeling: A Multidisciplinary Journal, 16(3), 397-438. https://doi.org/10.1080/10705510903008204.

Beard, J., Officer, A., \& Cassels, A. (2015). World report on ageing and health. World Health Organization, Geneva. Retrieved June 19, 2019 from http://www.who.int/ageing/publications/world-report-2015/en/.

Berg, A. I., Hassing, L. B., McClearn, G. E., \& Johansson, B. (2006). What matters for life satisfaction in the oldest-old? Aging and Mental Health, 10(3), 257-264. https://doi.org/10.1080/136078605004094 35.

Boccardi, M., \& Boccardi, V. (2019). Psychological wellbeing and healthy aging: Focus on telomeres. Geriatrics (Basel), 4(1), E25. https://doi.org/10.3390/geriatrics4010025.

Bowling, A., \& Gabriel, Z. (2007). Lay theories of quality of life in older age. Ageing \& Society, 27(6), 827-848. https://doi.org/10.1017/S0144686X07006423.

Brown, T. A. (2015). Confirmatory factor analysis for applied research. Methodology in the social sciences (2nd ed.). New York: The Guildford Press (US). 
Brown, R. T., Thomas, M. L., Cutler, D. F., \& Hinderlie, M. (2013). Meeting the housing and care needs of older homeless adults: A permanent supportive housing program targeting homeless elders. Seniors Housing \& Care Journal, 21(1), 126-135.

Bryant, L., Corbett, K. K., \& Kutner, J. S. (2001). In their own words: A model of health aging. Social Science and Medicine, 53(7), 927-941. https://doi.org/10.1016/s0277-9536(00)00392-0.

Burns, R. A. (2019). Age-related differences in the factor structure of multiple wellbeing indicators in a large multinational European survey. Journal of Happiness Studies. https://doi.org/10.1007/s1090 2-019-00077-y.

Cantarella, A., Borella, E., Marigo, C., \& De Beni, R. (2017). Benefits of well-being training in healthy older adults. Applied Psychology: Health and Well-Being, 9(3), 261-284. https://doi.org/10.1111/ aphw.12091.

Cantril, H. (1965). The pattern of human concerns. New Brunswick: Rutgers University Press.

Carstensen, L. L. (1992). Social and emotional patterns in adulthood: Support for socioemotional selectivity theory. Psychology and Aging, 7, 331-338. https://doi.org/10.1037//0882-7974.7.3.331.

Carstensen, L. L., Fung, H. H., \& Charles, S. T. (2003). Socioemotional selectivity theory and the regulation of emotion in the second half of life. Motivation and Emotion, 27(2), 103-123. https://doi. org/10.1023/A:1024569803230.

Charalampi, A., Michalopoulou, C., \& Richardson, C. (2018). Validation of the 2012 European social survey measurement of wellbeing in seventeen European countries. Applied Research in Quality of Life. https://doi.org/10.1007/s11482-018-9666-4.

Chei, C. L., Lee, J. M., Ma, S., \& Malhotra, R. (2018). Happy older people live longer. Age and Ageing, 47(6), 860-866. https://doi.org/10.1093/ageing/afy128.

Chen, F. F. (2007). Sensitivity of goodness of fit indexes to lack of measurement invariance. Structural Equation Modeling, 14(3), 464-504. https://doi.org/10.1080/10705510701301834.

Cherry, K. E., Marks, L. D., Benedetto, T., Sullivan, M. C., \& Barker, A. (2013). Perceptions of longevity and successful aging in very old adults. Journal of Religion, Spirituality \& Aging, 25(4), 288-310. https://doi.org/10.1080/15528030.2013.765368.

Cheung, G. W., \& Rensvold, R. B. (2002). Evaluating goodness-of-fit indexes for testing measurement invariance. Structural Equation Modeling, 9(2), 233-255. https://doi.org/10.1207/S15328007SEM090 2_5.

Chida, Y., \& Steptoe, A. (2008). Positive psychological well-being and mortality: A quantitative review of prospective observational studies. Psychosomatic Medicine, 70(7), 741-756. https://doi.org/10.1097/ PSY.0b013e31818105ba.

Cohen-Mansfield, J., Shmotkin, D., Blumstein, Z., Shorek, A., Eyal, N., Hazan, H., et al. (2013). The old, old-old, and the oldest old: Continuation or distinct categories? An examination of the relationship between age and changes in health, function, and wellbeing. The International Journal of Aging and Human Development, 77(1), 37-57. https://doi.org/10.2190/AG.77.1.c.

Cosco, T. D., Howse, K., \& Brayne, C. (2017). Healthy ageing, resilience and wellbeing. Epidemiology and Psychiatric Sciences, 26(6), 579-583. https://doi.org/10.1017/S2045796017000324.

Costello, A. B., \& Osborne, J. W. (2005). Best practices in exploratory factor analysis: Four recommendations for getting the most from your analysis. Practical Assessment, Research \& Evaluation, 10(7), 1-9. https://doi.org/10.7275/jyj1-4868.

Cresswell-Smith, J., Amaddeo, F., Donisi, V., Forsman, A. K., Kalseth, J., Martin-Maria, N., et al. (2019). Determinants of multidimensional mental wellbeing in the oldest old: A rapid review. Social Psychiatry Psychiatric Epidemiology, 54(2), 135-144. https://doi.org/10.1007/s00127-018-1633-8.

Delle Fave, A., Bassi, M., Boccaletti, E. S., Roncaglione, C., Bernardelli, G., \& Mari, D. (2018). Promoting well-being in old age: The psychological benefits of two training programs of adapted physical activity. Frontiers in Psychology, 9, 828. https://doi.org/10.3389/fpsyg.2018.00828.

Diener, E., \& Chan, M. Y. (2011). Happy people live longer: Subjective well-being contributes to health and longevity. Applied Psychology: Health and Well-Being, 3(1), 1-43. https://doi.org/10.111 1/j.1758-0854.2010.01045.x.

Diener, E., Emmons, R. A., Larsen, R. J., \& Griffin, S. (1985). The satisfaction with life scale. Journal of Personality Assessment, 49(1), 71-75. https://doi.org/10.1207/s15327752jpa4901_13.

Diener, E., \& Fujita, F. (1995). Resources, personal strivings, and subjective well-being: A nomothetic and idiographic approach. Journal of Personality and Social Psychology, 68(5), 926-935. https://doi. org/10.1037/0022-3514.68.5.926.

Diener, E., Suh, E. M., Lucas, R. E., \& Smith, H. L. (1999). Subjective well-being: Three decades of progress. Psychological Bulletin, 125(2), 276-302. https://doi.org/10.1037/0033-2909.125.2.276. 
Diener, E., Wirtz, D., Tov, W., Kim-Prieto, C., Choi, D., Oishi, S., et al. (2010). New wellbeing measures: Short scales to assess flourishing and positive and negative feelings. Social Indicators Research, 97(2), 143-156. https://doi.org/10.1007/s11205-009-9493-y.

Douma, L., Steverink, N., Hutter, I., \& Meijering, L. (2017). Exploring subjective well-being in older age by using participant-generated word clouds. The Gerontologist, 57(2), 229-239. https://doi.org/10.1093/ geront/gnv119.

Dunn, E. W., Aknin, L. B., \& Norton, M. I. (2008). Spending money on others promotes happiness. Science, 319(5870), 1687-1688. https://doi.org/10.1126/science.1150952.

Enders, C. K. (2010). Applied missing data analysis. New York: Guilford.

Enkvist, A., Ekstrom, H., \& Elmstahl, S. (2012). What factors affect life satisfaction (LS) among the oldest-old? Archives of Gerontology and Geriatrics, 54(1), 140-145. https://doi.org/10.1016/j.archg er.2011.03.013.

ESS Round 6: European Social Survey Round 6 Data. (2012). Data file edition 2.4. NSD-Norwegian Centre for Research Data, Norway-Data Archive and distributor of ESS data for ESS ERIC. Retrieved June 19, 2019 from https://doi.org/10.21338/nsd-ess6-2012. https://www.europeansocialsurvey.org/ data/conditions_of_use.html.

European Union. (2016). European framework for action on mental health and wellbeing. Retrieved from June 19, 2019 from https://ec.europa.eu/research/participants/data/ref/h2020/other/guides_for_appli cants/h2020-SC1-BHC-22-2019-framework-for-action_en.pdf.

Eurostat. (2016). Nearly 27 million people aged 80 or over in the European Union. Retrieved June 19, 2019 from https://ec.europa.eu/eurostat/documents/2995521/7672228/3-29092016-AP-EN.pdf/4b90f 6bb-43c1-45ed-985b-dfbe9564157a.

Eurostat. (2017). People in the EU-population projections. Retrieved from June 19, 2019 from https:// ec.europa.eu/eurostat/statistics-explained/index.php/People_in_the_EU_-_population_projections.

Forsman, A., Herberts, C., Nyqvist, F., Wahlbeck, K., \& Schierenbeck, I. (2013). Understanding the role of social capital for mental wellbeing among older adults. Ageing \& Society, 33(5), 804-825. https://doi. org/10.1017/S0144686X12000256.

Gallagher, M. W., Lopez, S. J., \& Preacher, K. J. (2009). The hierarchical structure of well-being. Journal of Personality, 77(4), 1025-1050. https://doi.org/10.1111/j.1467-6494.2009.00573.x.

Gelman, A. (2007). Struggles with survey weighting and regression modeling. Statistical Science, 22(2), 153-164.

Granerud, A., Imingen, I., \& Eriksson, B. (2017). Everyday life and wellbeing among the oldest elderly in Norway-A qualitative study. Open Journal of Social Sciences, 5, 97-111. https://doi.org/10.4236/ jss.2017.57007.

Hair, J. F., Black, W. C., Babin, B. J., Anderson, R. E., \& Tatham, R. L. (1998). Multivariate data analysis (Vol. 5, No. 3, pp. 207-219). Upper Saddle River, NJ: Prentice Hall.

Hansen, T., \& Slagsvold, B. (2012). The age and subjective well-being paradox revisited: A multidimensional perspective. Norsk Epidemiologi. https://doi.org/10.5324/nje.v22i2.1565.

Horn, J. L. (1965). Factors in factor analysis. Psychometrika, 30(2), 179-185.

Horn, J. L., \& McArdle, J. J. (1992). A practical and theoretical guide to measurement invariance in aging research. Experimental Aging Research, 18, 117-144.

Hu, L. T., \& Bentler, P. M. (1999). Cutoff criteria for fit indexes in covariance structure analysis: Conventional criteria versus new alternatives. Structural Equation Modeling, 6(1), 1-55. https://doi. org/10.1080/10705519909540118.

Huppert, F. A. (2009). Psychological well-being: Evidence regarding its causes and consequences. Applied Psychology: Health and Well-Being, 1, 137-164.

Huppert, F. A. (2014). The State of Wellbeing Science. Concepts, Measures, Interventions, and Policies. Volume 6. Interventions and Policies to Enhance Wellbeing. https://doi.org/10.1002/9781118539415. wbwell036.

Huppert, F. A., \& So, T. T. (2013). Flourishing across Europe: Application of a new conceptual framework for defining well-being. Social Indicators Research, 110(3), 837-861. https://doi.org/10.1007/s1120 5-011-9966-7.

Jaul, E., \& Barron, J. (2017). Age-related diseases and clinical and public health implications for the 85 years old and over population. Frontiers in Public Health, 5, 335. https://doi.org/10.3389/fpubh .2017 .00335 .

Jeffrey, K., Abdallah, S., \& Quick, A. (2015). Europeans' personal and social wellbeing: Topline results from Round 6 of the European Social Survey. London: Centre for Comparative Social Surveys.

Joshanloo, M. (2016). Revisiting the empirical distinction between hedonic and eudaimonic aspects of wellbeing using exploratory structural equation modeling. Journal of Happiness Studies, 17, 2023-2036. https://doi.org/10.1007/s10902-015-9683-z. 
Joshanloo, M., \& Weijers, D. (2019). A two dimensional conceptual framework for understanding mental well-being. PLoS ONE, 14(3), e0214045. https://doi.org/10.1371/journal.pone.0214045.

Kahneman, D., Krueger, A. B., Schkade, D. A., Schwarz, N., \& Stone, A. A. (2004). A survey method for characterizing daily life experience: The day reconstruction method. Science, 306(5702), 1776-1780. https://doi.org/10.1126/science.1103572.

Kaiser, H. F. (1960). The application of electronic computers to factor analysis. Educational and Psychological Measurement, 20, 141-151. https://doi.org/10.1177/001316446002000116.

Keyes, C. L. (1998). Social well-being. Social Psychology Quarterly, 61, 121-140. https://doi. org/10.2307/2787065.

Keyes, C. L. (2002). The mental health continuum: From languishing to flourishing in life. Journal of Health and Social Behavior, 43(2), 207-222.

Keyes, C. L. M., Shmotkin, D., \& Ryff, C. D. (2002). Optimizing well-being: The empirical encounter of two traditions. Journal of Personality and Social Psychology, 82, 1007-1022. https://doi. org/10.1037/0022-3514.82.6.1007.

Kim, J. O., \& Mueller, C. W. (1978). Factor analysis: Statistical methods and practical issues. Beverly Hills, CA: Sage.

Kline, R. B. (2016). Methodology in the social sciences. Principles and practice of structural equation modeling (4th ed.). New York: Guilford Press.

Lara, E., Martín-María, N., Forsman, A. K., Cresswell-Smith, J., Donisi, V., Ådnanes, M., et al. (2019). Understanding the multi-dimensional mental well-being in late life: Evidence from the perspective of the oldest old population. Journal of Happiness Studies. https://doi.org/10.1007/s10902-01900090-1.

Larson, J. S. (1996). The World Health Organization's definition of health: Social versus spiritual health. Social Indicators Research, 38(2), 181-192.

Linton, M. J., Dieppe, P., \& Medina-Lara, A. (2016). Review of 99 self-report measures for assessing wellbeing in adults: Exploring dimensions of wellbeing and developments over time. British Medical Journal Open, 6, e010641. https://doi.org/10.1136/bmjopen-2015-01064.

Lynn, P., Häder, S., Gabler, S., \& Laaksonen, S. (2007). Methods for achieving equivalence of samples in cross-national surveys: The European Social Survey experience. Journal of Official Statistics, 23(1), 107-124.

Marsh, H. W., Morin, A. J. S., Parker, P., \& Kaur, G. (2014). Exploratory structural equation modeling: An integration of the best features of exploratory and confirmatory factor analysis. Annual Review of Clinical Psychology, 10(3.1), 1-26. https://doi.org/10.1146/annurev-clinpsy-032813-153700.

Marsh, H. W., Muthén, B., Asparouhov, T., Lüdtke, O., Robitzsch, A., Morin, A. J. S., et al. (2009). Exploratory structural equation modeling, integrating CFA and EFA: Application to students' evaluations of university teaching. Structural Equation Modeling: A Multidisciplinary Journal, 16(3), 439-476. https://doi.org/10.1080/10705510903008220.

Meredith, W. (1993). Measurement invariance, factor analysis, and factorial invariance. Psychometrika, 58(4), 525-543. https://doi.org/10.1007/BF02294825.

Michaelson, J., Abdallah, S., Steuer, N., Thompson, S. \& Marks, N. (2009). National accounts of wellbeing: Bringing real wealth onto the balance sheet. London: NEF (The New Economics Foundation). Retrieved from June 19, 2019 from https://neweconomics.org/uploads/files/2027fb05fed1554 aea_uim6vd4c5.pdf.

Miret, M., Cabello, M., Marchena, C., Mellor-Marsá, B., Caballero, F. F., Obradors-Tarragó, C., et al. (2015). The state of the art on European wellbeing research within the area of mental health. International Journal of Clinical and Health Psychology, 2, 171-179. https://doi.org/10.1016/j.ijchp .2015.02.001.

Muthén, L. K., \& Muthén, B. O. (2012). Mplus user's guide (7th ed.). Los Angeles, CA: Muthén \& Muthén.

Ng, S. T., Tey, N. P., \& Asadullah, M. N. (2017). What matters for life satisfaction among the oldestold? Evidence from China. PLoS ONE, 12, e171799. https://doi.org/10.1371/journal.pone.0171799.

Nyqvist, F., Forsman, A. K., Giuntoli, G., \& Cattan, M. (2013). Social capital as a resource for mental wellbeing in older people: A systematic review. Aging and Mental Health, 17(4), 394-410. https:// doi.org/10.1080/13607863.2012.742490.

Poon, L. W., \& Cohen-Mansfield, J. (2011). Understanding well-being in the oldest old. New York: Cambridge University Press.

Rutkowski, L., \& Svetina, D. (2014). Assessing the hypothesis of measurement invariance in the context of large-scale international surveys. Educational and Psychological Measurement, 74(1), 31-57. https://doi.org/10.1177/0013164413498257.

Ryff, C. D. (1989). Happiness is everything, or is it? Explorations on the meaning of psychological wellbeing. Journal of Personality and Social Psychology, 57(6), 1069. 
Ryff, C. D., \& Keyes, C. L. M. (1995). The structure of psychological well-being revisited. Journal of Personality and Social Psychology, 69(4), 719-727. https://doi.org/10.1037/0022-3514.69.4.719.

Ryff, C. D., \& Singer, B. H. (2008). Know thyself and become what you are: A eudaimonic approach to psychological well-being. Journal of Happiness Studies, 9(1), 13-39. https://doi.org/10.1007/s1090 2-006-9019-0.

Ryff, C. D., Singer, B. H., \& Dienberg Love, G. (2004). Positive health: Connecting wellbeing with biology. Philosophical Transactions of the Royal Society of London, 359(1449), 1383-1394. https://doi. org/10.1098/rstb.2004.1521.

Salvador-Carulla, L., Lucas, R., Ayuso-Mateos, J. L., \& Miret, M. (2014). Use of the terms "wellbeing" and "quality of life" in health sciences: A conceptual framework. The European Journal of Psychiatry, 28(1), 50-65. https://doi.org/10.4321/S0213-61632014000100005.

Seligman, M. E. P. (2011). Flourish. New York, NY: Simon \& Schuster.

Smith, J., Borchelt, M., Maier, H., \& Jopp, D. (2002). Health and well-being in the young old and oldest old. Journal of Social Issues, 58(4), 715-732. https://doi.org/10.1111/1540-4560.00286.

Steptoe, A., Deaton, A., \& Stone, A. A. (2015). Psychological wellbeing, health and ageing. Lancet, 385(9968), 640-648. https://doi.org/10.1016/S0140-6736(13)61489-0.

Tennant, R., Hiller, L., Fishwick, R., Platt, S., Joseph, S., Weich, S., et al. (2007). The Warwick-Edinburgh mental wellbeing scale (WEMWBS): Development and UK validation. Health and Quality of Life Outcomes, 5, 63. https://doi.org/10.1186/1477-7525-5-63.

Tomini, F., Tomini, S. M., \& Groot, W. (2016). Understanding the value of social networks in life satisfaction of elderly people: A comparative study of 16 European countries using SHARE data. BMC Geriatrics, 16(1), 203. https://doi.org/10.1186/s12877-016-0362-7.

Topp, C. W., Østergaard, S. D., Søndergaard, S., \& Bech, P. (2015). The WHO-5 Wellbeing Index: A systematic review of the literature. Psychotherapy and Psychosomatics, 84(3), 167-176. https://doi. org/10.1159/000376585.

Van Lente, E., Barry, M. M., Molcho, M., Morgan, K., Watson, D., Harrington, J., et al. (2012). Measuring population mental health and social well-being. International Journal of Public Health, 57(2), 421430. https://doi.org/10.1007/s00038-011-0317-X.

Vandenberg, R. J., \& Lance, C. E. (2000). A review and synthesis of the measurement invariance literature: Suggestions, practices, and recommendations for organizational research. Organizational Research Methods, 3(1), 4-70. https://doi.org/10.1177/109442810031002.

VanderWeele, T. J. (2017). On the promotion of human flourishing. PNAS, 114(31), 8148-8156. https://doi. org/10.1073/pnas.1702996114.

Vanhoutte, B. (2014). The multidimensional structure of subjective well-being in later life. Journal of Population Ageing, 7(1), 1-20. https://doi.org/10.1007/s12062-014-9092-9.

Wang, J., \& Wang, X. (2012). Structural equation modeling: Applications using Mplus. Wiley/Higher Education Press. Retrieved from https://www.oreilly.com/library/view/structural-equation-modeling/97811 18356302/.

Wang, H., Zhao, E., Fleming, J., \& on behalf of the CC75C study collaboration. (2019). Is loneliness associated with increased health and social care utilisation in the oldest old? Findings from a populationbased longitudinal study. British Medical Journal Open, 9, e024645. https://doi.org/10.1136/bmjop en-2018-024645.

Winship, C., \& Radbill, L. (1994). Sampling weights and regression analysis. Sociological Methods \& Research, 23(2), 230-257. https://doi.org/10.1177/0049124194023002004.

World Health Organization. (2004). Promoting mental health: Concepts, emerging evidence, practice (Summary Report). Geneva: World Health Organization.

World Health Organization. (2013). Mental health action plan 2013-2020. Retrieved from June 19, 2019 from https://www.who.int/mental_health/publications/action_plan/en/.

Publisher's Note Springer Nature remains neutral with regard to jurisdictional claims in published maps and institutional affiliations. 


\section{Affiliations}

Valeria Donisi ${ }^{1}$ - Federico Tedeschi ${ }^{1}$. Juan Luis Gonzalez-Caballero ${ }^{2}$.

Johanna Cresswell-Smith ${ }^{3}$. Elvira Lara ${ }^{4,5,6} \cdot$ Marta Miret $^{4,5,6} \cdot$ Anna K. Forsman $^{7}$. Kristian Wahlbeck ${ }^{3} \cdot$ Francesco Amaddeo $^{1} \cdot$ Jorid Kalseth $^{8}$

1 Department of Neurosciences, Biomedicine and Movement Sciences, University of Verona, Verona, Italy

2 Department of Statistics and Operational Research, Faculty of Medicine, University of Cádiz, Cádiz, Spain

3 Mental Health Unit, National Institute for Health and Welfare, Helsinki, Finland

4 Department of Psychiatry, Universidad Autónoma de Madrid, Madrid, Spain

5 Centro de Investigación Biomédica en Red de Salud Mental. CIBERSAM, Instituto de Salud Carlos III, Madrid, Spain

6 Department of Psychiatry, Hospital Universitario de La Princesa, Instituto de Investigación Sanitaria Princesa (IIS-Princesa), Madrid, Spain

7 Faculty of Education and Welfare Studies, Health Sciences, Åbo Akademi University, Vaasa, Finland

8 Department of Health Research, SINTEF Digital, Trondheim, Norway 